\title{
Facilitating scholarly communication in African Studies
}

\author{
Titia van der Werf-Davelaar *
}

\begin{abstract}
Web publishing and its technical possibilities, and the open access movement that has accompanied it, have resulted in a number of tendencies with mixed implications for scholarly communication. This article examines the impact of these changes in the field of the African studies, where the North-South divide in scientific publishing poses an additional challenge to the issues at stake. It looks at several initiatives taken by the Africanist scholarly community in the Netherlands to bridge the divide, in particular the establishment of a digital platform for African studies. It concludes that these initiatives are all geared towards redressing the balance and establishing open scholarly communication on an equal footing, but that true open access can only be achieved if practised both ways (by North and South) and not at the expense of academic quality standards. In addition, it requires the active commitment of each and every individual scholar. This commitment still needs to grow in Africanist circles.
\end{abstract}

\section{Introduction}

In the past ten years, research in progress has become more visible through web publishing. Academic research centres publish newsletters, research papers, working papers, pre-prints, seminar reports and conference proceedings, including digital video presentations. Individual researchers create their own personal web pages listing overviews of their publications, research projects, teaching courses, presentations and talks. Technological advances in web publishing make this possible. Publishing on the web helps individual researchers and research units to raise their profile and present themselves to the community on campus and beyond, but gradually, as web publishing becomes an accepted medium for information dissemination, it serves other goals as well. It speeds up the communication of research results and helps reach specific target groups and larger audiences in an effective manner. It also raises pertinent questions about access to scholarship and the business models of traditional publishing. And it opens up new horizons for the advancement of free access to information and the availability of publications.

This article explores aspects of this transformation in academic publishing, looking at it from the perspective of the Africanist community in the Netherlands. It is based on experiences and insights gained during the course of an innovative project aimed at establishing a digital platform for scholarly communication in African studies.

North-South divide in scholarly publishing Although the North-South divide in scholarly publishing is a recognized fact, most emphasis is on stimulating the flow of information from the developed

* Titia van der Werf-Davelaar is Head of the Library, Afrika-Studiecentrum, Leiden, The Netherlands. 
North to the developing South [Britz and Lor, 2003]. Library book donation programmes from all over the world ship millions of books a year to African libraries and schools. Negotiations with publishers have resulted in journals and databases being made available for free or at heavily discounted prices through programmes like AGORA, HINARI, eIFL, and PERI, in relation to the leading journals in medicine, agriculture, environmental and social sciences. Together with these programmes much training has taken place. In the field of African Studies, research centres like the Nordiska AfrikaInstitutet in Uppsala and the Afrika-Studiecentrum in Leiden, make it a popint of honour to distribute their publications free in Africa. But notwithstanding these efforts to redress the imbalance between North and South, it appears many African libraries and research institutes do not benefit because they are not aware of the availability of programmes and access deals [Gwynn, 2004].

What happens to the information flow in the other direction - from South to North? Small-scale programmes have been initiated and co-funded by western donors to stimulate the development of e-journals in Africa, like the African e-Journals Project and $\mathrm{AJOL}^{\mathrm{n}}$. Even more promising are initiatives from within the African research community, such as CODESRIA's publication programme, which is geared towards developing outlets for African scholarship. CODESRIA publishes ten bilingual and multilingual journals, half of them freely available online [Nyamnjoh, 2004]. Self-publishing and the movement for open access ${ }^{1}$ to scholarly literature offer unprecedented opportunities for academics from the developing world to disseminate their research results and to participate on an equal footing in international scientific discourse. They can download content that would normally be unavailable to them had it not been subsidized and they can upload content that would normally be excluded from prestigious journals and library collections. Scholars and students who join research institutes abroad for guest fellowships and $\mathrm{PhD}$ programmes respectively, can publish their works online and share their findings with their home universities. Those who stay abroad to pursue an academic career can engage with their home-based scientific community in a more meaningful way, now that geographical barriers have been overcome by Internet technologies. It is not surprising then that Latin American and African academics in particular, rather than their North American and European counterparts, are embracing the new technology and its revolutionary opportunities for scholarly communication [Holdom, 2005]. This in turn gives rise to concerns regarding equal participation in the free flow of information between North and South. If scholars in developing countries eagerly disseminate their work in the public domain whilst those in developed countries stay relatively reluctant to do so, the established control mechanisms of academic publishing will remain in place and the free and uncontrolled dissemination of research results on the Web will become synonymous with unprofessional practice and poor quality output, exacerbating the imbalance in scholarly publishing between North and South.

\section{The Connecting-Africa initiative}

Against this background and from informal discussions between the Centre for Development Studies in Groningen and the African Studies Centre in Leiden

See: The Budapest Open Access Initiative (http://www.soros.org/openaccess/ read.shtml), The Bethesda Principles (http://www.biomedcentral.com/openaccess/ bethesda/) and The Berlin Declaration (http://www.zim.mpg.de/openaccess-berlin/ berlindeclaration.html). 
about the dissemination of grey literature, the idea emerged to start a web platform facilitating scholarly communication in African studies. With the proliferation of freely available research reports and self-published work-inprogress, the platform would need to gather and filter online studies and materials relevant to research on Africa. Because scholarly communication is more than the publication and dissemination of research, the platform would also need to bring the academic experts on Africa together in a virtual community to facilitate the flow of ideas and the need for discussion and to stimulate professional interactions and networking processes. Starting from this set of requirements, the African Studies Centre in Leiden developed a pilot service and called it Connecting-Africa.

In the past two years, the scope of the platform has been limited to African research in the Netherlands. The rationale behind this is to ensure a critical mass of involvement by the Dutch research community of Africanists and to help enhance the visibility of African studies in the Netherlands. There are over 400 Africanists scattered across more than a hundred university departments and research institutes in the country, and it is assumed that bringing this scattered community together in a virtual environment will help increase knowledge exchange and networking activity. It is expected that a critical mass of participation by Dutch Africanists will lead to spin-offs across Europe, Africa and the US.

At the same time it is hoped that this joint effort will lead to novel solutions to redress the imbalance between North and South and to stimulate scientific dialogue between Dutch Africanists and their African colleagues on an open and equal footing, unhampered by current impediments in scholarly publishing. It is believed this approach could be successful in the specialized area of African studies, in which the vested interests of the publishing industry are relatively low and the commitment of Africanists to support research and education in Africa is high.

Setting up a database with information about Africa experts and collecting information about their publications and other research requires important investments in time and energy, and in the long term a sustainable budget that does not rely on project funding or voluntary contributions. Sustained support from the network members and an administrative capacity to manage the network are essential. The proposed model is, therefore, to develop Connecting-Africa as a distributed effort with federated access to content from university repositories, library catalogues and other resources, including African studies databases with information on researchers and research-related institutes and projects. In this way the maintenance of Connecting-Africa lies with parties that already serve the African studies community and is a natural extension of their institutional tasks and responsibilities. For the researchers involved, the community would be without borders, although in reality it would be managed by different African studies centres situated in different countries across the world. In this way Connecting-Africa could grow to become a truly global network that is scalable and sustainable.

The Connecting-Africa pilot project is based on existing and newly emerging building blocks. In 2003 the African Studies Centre in Leiden took over the database of Africanists which the Netherlands organization for international cooperation in higher education (Nuffic) had been keeping up-to-date from 1992 onwards, but had had to discontinue due to lack of funding from donors. This database with rich information on the thematic and regional expertise of 
Africanists forms the basis of the Connecting-Africa community portal. Also in 2003, a new infrastructure of digital academic repositories was being set up in the Netherlands (DARE) and formed a potentially promising source of publications and research materials on Africa. It was therefore decided to base the search module of Connecting-Africa on title information stored in these institutional repositories.

\section{Institutional repositories}

An institutional repository is like a digital 'treasure chest', containing the digitally recorded intellectual output of the research institution. It is a wellmanaged storage and archiving system. The principle is simple. Researchers place their year's research output with accompanying title information in the institutional repository and grant their university permission to distribute and preserve their work. The materials can consist of publications, research data and supporting materials (e.g. audio or video). In order for the content to be more visible and searchable worldwide, most repositories make the title information freely and easily available for re-use by third parties, enabling them to enrich their search services with these metadata. ${ }^{2}$ In practice, this means that anyone can find a work in a repository through a search engine or other service, for example via Google, without knowing which repositories exist, where they are located, or what they contain. In this way academic repositories make their content widely available and function as ubiquitous content providers. They can be regarded rather like a utility providing a basic service like electricity or gas. By contrast, self-publishing by individual researchers on their personal web pages is of a more incidental nature, meant for instant wider dissemination only, and not for long lasting access and archiving purposes.

\section{Copyright and publishers}

Researchers need to be the copyright holders for them to be able to grant permission to the institutional repository to distribute and preserve their work. However, in academic publishing it is common practice for authors to give away the entire copyright to the publisher in return for the latter taking care of the complete publishing process. This means that the publisher has exclusive control over access to the content. This is important to realize in order to understand the paradoxical position libraries find themselves in as access providers in the digital environment. Because publishers organize editorial boards and peer-reviews as part of the publishing process, they also play an important role in helping to structure panels of academic experts and deciding on new marketable titles and themes for journal special issues. Publishers have built strong relationships of trust with their authors and have succeeded in producing reputable journals and monograph series with a strong brand visibility. This has led to a dependency relationship in which publishers effectively have control over the valuation of research output, as measured by journal rankings and other impact factors, whilst authors carry out quality control through their roles as academic referees [Guédon, 2001].

By contrast, self-publishing on the web basically leads to the uncontrolled reproduction, distribution and availability of publications, mass usage instead of

${ }^{2}$ The metadata is made available through the Open Archives Initiative Protocol for Metadata Harvesting (OAI-MHP). 
targeted usage and the growing problem of Internet plagiarism. As research enters the public arena, the research process and the valuation of research threaten to become everybody's business. This is very comparable to the 'democratization's of music a generation or two ago, which was made possible by the introduction of recordplayers and the radio. But the Internet amplifies this trend to an unprecedented degree. Internet radio and the webcasting industry are luring customers away from traditional media sources by providing access to thousands of global radio broadcasts in real time, with increases of over $750 \%$ of audience listening time [WIPO survey, 2002]. For academia, the prospect that research becomes a commodity at the beck and call of the unchecked forces of consumption is alarming and threatening. Academics do not regard the general public as a key target group. Web citation rates may well explode exponentially, but what will they say about the real value to science of a particular piece of research? Who will be the gatekeepers of science? Who will safeguard the credibility of academic authors? It becomes clear then that copyright is not the only issue at stake; it is just one mechanism in a complex framework built to support the scientific process and instrumental to its institutionalization.

\section{African studies entering the African arena}

Researchers are just beginning to become aware of the forces at play and to analyse the drastic consequences of the transformations taking place in scholarly communication. In the social sciences in particular, these transformations will intensify the social appropriation of sociological concepts and interpretations. As sociology enters the public arena, intensified interactivity may blur the distinctions between observers and actors, between science and ideology and affect human agency in unprecedented ways. What will be the effect on African studies, the study of African societal processes? How will openness and interactivity transform this research activity which is still dominated by western perspectives, as African studies move into the African arena? Will it contribute to a greater participation of African scholars in Africanist circles? Will it lead to the disintegration of African studies as a discrete field and the full-fledged participation of African perspectives in the wider academic discourse? Will it accelerate cross-pollination between North and South? What will be the effects on current development thinking? Will it lead to more plurality and diversity? Will it reinforce the endorsement by African scholars of the dominant western social and cultural values, theories and methodologies, research themes and political agendas? These are tantalizing questions posed by the transformations taking place in scholarly communication. These transformations are triggered by technological innovations but the direction these transformations take is ultimately in the hands of the stakeholders.

\section{Stakeholders in the open access debate}

There are several stakeholders. Academic publishers have been mentioned as gatekeepers of science. Open access has the potential to undermine, if not remove, publishers' commercial viability. In the open access debate they are therefore weighing up the risks and benefits. They are experimenting with

\footnotetext{
3 'Democratization' is used in a socio-economical sense: meaning that it is no longer a commodity of comparative luxury enjoyed by the privileged few.
} 
different business models, at first in fields such as physics and the life sciences, but pressure is building on publishers of other disciplines to follow suit.

Research libraries are the safekeepers of science: they collect and preserve the records of science for academia, now and in the future. Their role is to ensure optimal access to, and preservation of, the published results of research. The upwards trend in journal subscription rates charged by commercial publishers has forced many libraries to cut back on the number of journal subscriptions. In the Netherlands, this trend is exacerbated by the higher VAT on e-journals $(19 \%)$ as compared to print journals $(6 \%)$. With e-journals, publishers have introduced licensing models to replace conventional subscription models, keeping ownership and control of digital materials in their hands. In reaction to this trend libraries have started to form consortia to negotiate licensing conditions and access terms with publishers, and at the same time they are experimenting with open access coupled with the setting up of institutional repositories. In the Netherlands, the development of academic repositories under the DARE programme is linked to the open access debate and to the long-term digital preservation programme of the national library. Similarly, the Massachusetts Institute of Technology (MIT) is investing in open sharing and open access technologies. Together with the Hewlett-Packard Company, MIT Libraries have developed DSpace, a digital repository software platform. With DSpace, MIT aims to store the Institute's entire intellectual output, including data and course materials. The DSpace system was officially released as open source at the end of 2002, to coincide with a symposium held at MIT on the problems of scholarly communication. Early in 2005 there were more than a hundred DSpace repositories installed in 28 countries around the world. This shows how the forces driving these developments are technology driven. But mounting and maintaining publications online and developing new digital functionalities also require substantial funds. And publishers are doing the same, investing millions of euros in computer technology for their digital publishing platforms. As we move into the digital environment where manuscripts become part of the search environment and references are linked to other electronic documents, and access is regulated by rights management mechanisms, and preservation is driven by early warning software, the customary sequence of steps characteristic of the print environment merge and the distinctive tasks of publishers and libraries become blurred. As a result, huge commercial and public investments are competing to develop new solutions to old problems and to find new ways of communicating science in the digital age.

In the midst of all this, academics seem ill-informed about the issues at stake and the power play that is going on between publishers and libraries. This is somewhat surprising since academics are the main stakeholders in scholarly communication, both as authors and readers. They are not aware of the room for negotiation over the grant of rights to publishers. Basically they seem quite happy for the publishers to take charge of their copyright. Interestingly, it appears they are generally satisfied with the information systems currently in place. As authors, they place most value on journals that target key readers and carry the greatest authority, and as readers they are generally content with their (fully subsidized) access to the journal literature [Rowlands, 2004]. Authors of open access publications, by contrast, have become more aware of the issues at stake and indicate a strong desire to change current practices in the transfer of copyright. They find the re-use situation in the traditional publishing model 
frustrating, a situation in which one-third of authors re-use their own publications without asking permission from their original publishers [Hoorn and Graaf, 2005].

\section{The position of Africanists}

Africanists in the Netherlands in general fit into this overall picture concerning current publishing and access systems, but there are some striking additional points to report [DARC workshop report, 2005]. They regret that overemphasis on impact factors is forcing them to publish in journals which are not read by their fellow African researchers, due to the inadequate North-South flow of scientific literature. If they were to target their preferred reader groups, they would have to publish in African journals which have low citation rates. Since 2003, CERES, the national research school for resource studies for development, operates a new journals ranking system in the social sciences. This system includes journals from developing countries which do not appear in the ISI journal rating and ranks them in the categories 'other refereed journals', 'non-refereed journals for academic readers' and 'all others' [CERES ranking system, 2005]. The African Studies Centre in Leiden contributed a list of journal titles published in Africa to the CERES system. In this way, Africanists in the Netherlands who are evaluated on the basis of the CERES system are encouraged to publish in African journals.

Another interesting model to include African publications in the ranking systems dominated by the North is through cooperative publishing between African universities and universities in the North. The collaboration between the University of Ouagadougou and the University of Groningen, which started 25 years ago and which has been recently evaluated [Bilan et perspectives, 2005], is a case in point. The most recent initiative in this collaborative framework is the co-publication of a new journal, fournal Africain des sciences de l'environnement (JASE).

Finally, another form of lifting barriers to the dissemination of African publications should be mentioned. The library of the African Studies Centre in Leiden has intensified its policy of subscribing to relevant African journals, discarding some more general development studies titles available at most university libraries. The aim is to build a journal collection with $40 \%$ of the titles coming from Africa and to give priority to indexing and abstracting articles of those titles. The library's catalogue, with article-level titles and abstracts, is freely available online and its contents are aggregated and linked into bibliographical databases, such as Africa-Wide: NiPAD, thereby contributing to the wider dissemination of African scholarship.

Even if speedy communication of research results and pre-print versions of publications are not felt to be critical in many fields of African studies, Africanists do sympathize with the concept of web publishing because they see interesting opportunities to reach their target audience. On the other hand, they are very concerned that readers on the Internet are unable to distinguish between works of different quality and different types of publication such as, for example, peer-reviewed work, research-in-progress and dissertations. In particular, students and inexperienced readers should be clear about the variable quality of research and able to differentiate authoritative work from poor work. Most Africanists make some of their materials available on their home page or institutional web site. Learning materials and seminar 
presentations, however, are not always seen as suitable for dissemination, because they can easily be misinterpreted if not understood in the context of the full lecture or presentation. A handout, for example, with shorthand notes about specific African events or leaders becomes a politically sensitive document if used out of context. For the newly established research masters degrees in African studies in the Netherlands, the University and Research Centre in Wageningen will develop a controlled e-learning repository to access copyright-cleared digital learning materials. This repository will be connected to the digital learning environments of the participating universities.

\section{Filling the repositories with African studies materials}

The strategy being followed by the Connecting-Africa project to fill the repository with African studies materials is time consuming but effective. Africanists are approached by their colleagues and invited to participate. They hand over their publications list and their major publications dating from before 1997 are collected in paper form and digitized. It is generally accepted that before 1997 authors did not sign away the rights of electronic publication because until then publishers did not consider the future possibility of publishing articles electronically. For works published in 1997 and after, publishers are contacted to ask permission for archiving a copy in the institutional repository. Publishers's replies and their copyright policies are recorded on a web page of the Connecting-Africa site, so as to inform fellow Africanists. Model agreements for researchers to help them avoid signing away their entire copyright in future are also available on the website. All digital publications that have been scanned and cleared in this way are then entered into the repository.

Connecting-Africa collects title information from 29 repositories on a weekly basis. To date it has harvested a total of 258,448 records and filtered 1,470 relevant records on Africa $(0.56 \%)$. Of these 1,017 refer to full-text publications readable online.

\section{Enlarging and diversifying the communities}

Nearly half of the Dutch Africanist community are members of the

Connecting-Africa portal. Many more specialists on Africa both in and outside the Netherlands want to join: researchers from Belgium and Germany, retired researchers, African graduates not affiliated to a university in the Netherlands but living in the country, NGO staff members, journalists, etc. ConnectingAfrica will implement open source forum software to accommodate the demand for different virtual communities and it will be interesting to follow what happens to these communities. Furthermore, CERES, and the African Studies Centre and the International Institute for Asian Studies in Leiden, are now working on a new project proposal with the aim of replicating the Connecting-Africa model for other area studies: Connecting-Asia, ConnectingLatinAmerica, Connecting-theCaribbean, etc. To this end the ConnectingAfrica platform will be based on a new architecture for web services delivery (SOAP), enabling the distributed maintenance of data stores with information about experts, organizations and publications. Finally, Connecting-Africa needs to be adopted by the African research community in Africa, in order to become truly Africa-centred. Plans to share the Connecting-Africa platform with the pan-African network of researchers affiliated to CODESRIA are being made. 


\section{Conclusion}

The Connecting-Africa initiative is a successful pilot project and it holds out great promise for future expansion and enlargement of the intellectual community. It is too early, however, to assess how far it will be instrumental in facilitating scholarly communication in African studies. To date, most Africanists have not shown a pro-active attitude concerning changes in academic publishing and open access, but they do sympathize with the idea of increasing access to their own publications in Africa and reaching scholars in Africa. Will this be sufficient incentive to fill the repositories? Looking at the heavily institutionalized scientific process in the North, with its age old traditions and vested interests, it is understandable that transformation and adaptation takes time. But it also raises questions. Is the print tradition a barrier or a pre-requisite for developing digital publishing models? Can Africa leapfrog into the digital age and bypass the developmental stages of the print-based knowledge economy? It is undeniable that there is a North-South divide in scholarly publishing and an imbalance of information flows, but this should not be redressed at the expense of academic quality standards. There are concerns that the open access movement, because it is being so eagerly embraced by developing countries in contrast to the caution being shown in developed countries, will exacerbate the imbalance in scholarly publishing between the North and the South. It may perhaps be too early for open access on an equal basis, but there are other ways to achieve more equity, as demonstrated by efforts to stimulate good publishing practices from within Africa, by the incorporation of African journals in European and American systems of research valuation, by cooperative publishing between universities across the Northern and Southern continents and by increased dissemination of African scholarship through indexing and abstracting services. The African Studies platform, Connecting-Africa, is a new initiative that fits in this framework. It is based on technologies designed to facilitate open communication and transparency of knowledge interactions between experts. It is a platform designed to support the 'visible college' in African studies as opposed to the 'invisible college'.

\section{References}

Bilan et Perspectives d'une coopération scientifique durable Burkina Faso-Pays-Bas. Draft, September 2005.

http://www.rug.nl/ifs/files/webroot/dev/cds/africanNetworks/ DRAFTSEPT2005.pdf

Britz, J.J. and Lor, P.J. (2003) 'A moral reflection on the information flow from South to North: an African perspective'. Libri, vol. 53, pp. 160-173.

CERES (2005) The CERES system of research valuation. Http:ceres.fss.uu.nl2005[1].The CERES system of research valuation.pdf

DARC workshop report (2005). Copyrights and institutional repositories (in Dutch). http://www.ascleiden.nl/Pdf/Darc/Verslag-workshop-03-webversie.pdf

E-journals: Developing Country Access Survey 2002 (2003). 'A survey of the activities and views of publishers regarding access to their information within the developing world either free or at reduced cost'. INASP Report. http://www.inasp.info/pubs/survey.html 
Guédon, J-C. (2001) 'In Oldenburg's Long Shadow: Librarians, Research Scientists, Publishers, and the Control of Scientific Publishing'. Proceedings ARL Membership Meeting. http://www.arl.org/arl/proceedings/138/ guedon.html

Gwynn, S. (2004) 'Journal access programmes in African university libraries'. INASP Newsletter. No. 25. http://www.inasp.info/newslet/mar04.html\#2

Holdom, S. (2005) 'E-journal proliferation in emerging economies: The case of Latin America'. Literary and Linguistic Computing. doi:10.1093/1lc/fqi033

Hoorn, E. and Graaf, M. van der, (2005) 'Towards good practices of copyright in Open Access Journals. A study among authors of articles in Open Access journals. JISC-SURF copyright programme'. http://www.surf.nl/publicaties/index2.php

Nyamnjoh, Francis B. (2004) 'From publish or perish to publish and perish: What the "Africa's 100 Best Books" tell us about publishing Africa'. Paper presented at the African Studies Association of the UK Biennial Conference: Debating Africa?, Goldsmith College, University of London, September 2004.

Rowlands, I., Nicholas, D. and Huntingdon, P. (2004) 'Journal publishing: what do authors want?' Survey by the Centre for Information Behaviour and the Evaluation of Research at City University London. http://ciber.soi.city.ac.uk/ciber-pa-report.pdf

WIPO (2002) 'Intellectual Property on the Internet: A Survey of Issues'. http:/www.wipo.int/copyright/ecommerce/en/pdf/survey.pdf

Zuccala, A. (2005) '. Fournal of the American Society for Information Science and Technology.

http://individual.utoronto.ca/azuccala_web/InvisibleCollege.pdf

Acronyms and Web addresses

African e-Journals Project http://africa.msu.edu/AEJP/proj-ejournal.htm

AGORA - Access to Global Online Research in Agriculture http://www.aginternetwork.org/en/

AJOL - African Journals OnLine http://www.inasp.info/ajol/index.shtml

ASA-O: African Studies Abstracts Online http://www.ascleiden.nl/Library/Abstracts/ASA-Online/

CERES: Research School for resource studies for development. Utrecht. http://ceres.fss.uu.nl/

CODESRIA: Council for the Development of Social Science Research in Africa. Dakar. http://www.codesria.org/

Connecting-Africa http://www.connecting-africa.net/

DARC: Distributed Africana Repositories Community (DARE projects 20032004 and 2004-2006) http://www.ascleiden.nl/Projects/Darc/

DARE: Digital Academic Repositories Programme in the Netherlands. http://www.surf.nl/en/themas/index2.php?oid=7

eIFL.net - Electronic information for Libraries http://www.eifl.net/

HINARI - Health InterNetwork Access to Research Initiative 
http://www.who.int/hinari/en/

ISI - Institute for Scientific Information http://www.isinet.com/

JASE - Journal Africain des sciences de l'environnement. http://cepape.univ-ouaga.bf/autre/word/jasee.htm

MIT - Massachusetts Institute of Technology http://web.mit.edu/

OAI - Open Archives Initiative http://www.openarchives.org/

PERI - Programme for the Enhancement of Research Information http://www.inasp.info/peri/index.shtml

SOAP - Simple Object Access Protocol http://www.w3.org/2002/ws/Activity 